\title{
Three-dimensional numerical and experimental study of fracture saturation in panel paintings
}

\author{
Mohammad Yaghoub Abdollahzadeh Jamalabadi ${ }^{1} \cdot$ Noemi Zabari $^{1}$. \\ Łukasz Bratasz ${ }^{1}$ (D)
}

Received: 9 March 2021 / Accepted: 7 September 2021 / Published online: 22 September 2021

(c) The Author(s) 2021

\begin{abstract}
Panel paintings_complex multi-layer structures consisting of wood support and a paint layer composed of a preparatory layer of gesso, paints, and varnishes-are among the category of cultural objects most vulnerable to relative humidity fluctuations and frequently found in museum collections. The current environmental specifications in museums have been derived using the criterion of crack initiation in an undamaged, usually new gesso layer laid on wood. In reality, historical paintings exhibit complex crack patterns called craquelures. The present paper analyses the structural response of a paint layer with a virtual network of rectangular cracks under environmental loadings using a three-dimensional model of a panel painting. Two modes of loading are considered-one induced by one-dimensional moisture response of wood support, termed the tangential loading, and the other isotropic induced by drying shrinkage of the gesso layer. The superposition of the two modes is also analysed. The modelling showed that minimum distances between cracks parallel to the wood grain depended on the gesso stiffness under the tangential loading. Despite a nonzero Poisson's ratio, gesso cracks perpendicular to the wood grain could not be generated by the moisture response of the wood support. The isotropic drying shrinkage of gesso produced cracks that were almost evenly spaced in both directions. The modelling results were cross-checked with crack patterns obtained on a mock-up of a panel painting exposed to several extreme environmental variations in an environmental chamber.
\end{abstract}

Łukasz Bratasz

lukasz.bratasz@ikifp.edu.pl

1 Jerzy Haber Institute of Catalysis and Surface Chemistry Polish Academy of Sciences, 30-239,

Kraków, Poland 


\section{Introduction}

As discussed in detail in a recent paper on fracture processes in paint layers on wood (Bratasz et al. 2020), the material served for centuries as a support for paintings in Europe. Panel paintings are among the most precious and frequently exhibited categories of heritage objects, which at the same time are most vulnerable to relative humidity $(\mathrm{RH})$ and temperature fluctuations. Paintings on the wood are complex multi-layer structures composed of wood support sized with animal glue and a paint layer consisting of a preparatory layer of gesso-a mixture of animal glue and white inert solid - to produce a smooth painting surface, and paints and varnishes on the top. All materials constituting painted wood are humidity sensitive: they swell when they gain moisture and shrink when they lose it, which generates moisture-induced stresses owing to materials' different dimensional responses to the loss or gain of moisture. Wood is anisotropic and its moisture-related dimensional changes vary in its three principal anatomical axes-longitudinal, or parallel to the grain, radial, and tangential. The most pronounced moisture response is in the tangential direction, and it halves in the radial one. For practical purposes, wood can be considered dimensionally stable parallel to its grain.

The mismatch in the moisture response of gesso and wood support in the direction across the grain, especially the most responsive tangential direction, has been identified as the worst-case condition that can lead to cracking in the entire paint layer. The gesso layer experiences tension during wood swelling, which leads to cracking if the strain generated by the wood support goes beyond the critical level (Mecklenburg et al. 1998). Bosco et al. (2020, 2021) analysed the cracking mechanism in brittle coatings under moisture loads and applied it to historical paintings. The notion that the deterioration of objects is related to indoor climate instability, existed long before first museums were created. The concept of stabilizing humidity changes in the environment of paintings was gradually reflected in good practice and housekeeping rules, which over the last century evolved into the climate specifications for museums we know today. Until the beginning of 1990s, these specifications were based on the technical capabilities of climate control systems rather than experimental or theoretical evidence of collections needs. As a result, climate control specifications were very stringent — and in many museums still are-both in temperature (typically 21 or $22 \pm 1{ }^{\circ} \mathrm{C}$ ) and $\mathrm{RH}$ (typically $50 \pm 5 \%$ ) (Thomson 1986). Only since 1990s, the dimensional response of materials to climatic changes and the critical levels of strain at which the materials began to deform plastically or fracture have been studied in the laboratory (Mecklenburg et al. 1998; Rachwał et al. 2012), which has led to the development of evidence-based environmental specifications for collections of historical objects (Ashrae, 2019; Bickersteth 2016). Moderate variations within the approximate $\mathrm{RH}$ range of $\pm 10 \%$ around the long-term average $\mathrm{RH}$ of $50 \%$ have been indicated as safe for paintings. Implementation of evidence-based, more relaxed environmental specifications in numerous museums has shown that even a slight relaxation of the specifications can significantly reduce energy consumption and the use of fossil fuels (Kramer et al. 2016; Smithsonian 2015). 
The above 'safe' RH range has been derived using the extreme value of a conservative criterion for the gesso's crack initiation in undamaged, usually new, material. In reality, painted objects, especially panel paintings, with their long environmental history, exhibit complex crack patterns called craquelures (Giorgutti-Dauphiné and Pauchard 2016; Pauchard and Giorgiutti-Dauphiné 2020). Cracks in paintings can be referred to as 'edge fractures' as they are initiated from the free surface. The craquelure patterns in a painting are related both to drying shrinkage of a pictorial layer, and to environmental and physical impacts which the painting experienced in its history. The terms 'drying' and 'aging' cracks were used to describe these two groups of crack, respectively (Bucklow 1997). Krzemień et al. (2016) investigated the development of cracks from drying shrinkage in a freshly prepared gesso layer. They demonstrated that attaining the ultimate permanent drying shrinkage of the gesso was achieved after repeated cycling between low and high RH levels, which can be explained by diffusing out free volume locked in the material until the equilibrium state. As the craquelure patterns stabilized after a limited number of cycles (30 for a $1 \mathrm{~mm}$ thick layer), drying cracks in gesso developed fully after a relatively short period of probably no more than several years after the painting was executed and exposed in a building with unavoidably uncontrolled climate.

Craquelure patterns can be categorized based on many features such as direction (craquelure patterns showing no direction, cracks parallel or perpendicular to the wood grain), shape (jagged and straight cracks with square islands, smooth and curved cracks and irregular islands), distance between cracks, thickness (cracks of non-uniform or uniform thickness), and network (secondary, connected, broken or ordered networks). Drying of the gesso leads to isotropic 'mud crack patterns' as the principal stresses in directions parallel to the free surface are similar. In turn, mismatch in moisture-induced swelling of gesso and wood support leads to a set of parallel cracks as stress distribution in the gesso is dominated by one principal stress perpendicular to the wood grain (Bucklow 2000). In Figs. 1 and 2, some of the simplest craquelure patterns found in paintings are presented.

Fracture mechanics provides a useful approach to analysis of processes occurring in bilayer materials undergoing dimensional changes (Hutchinson and Suo 1992; Ma et al. 2019; Shevchuk and Silberschmidt 2005; Wu and Pollard 1995; Yin 2010; Zhang et al. 2021). As the substrate of a bilayer system expands, the maximum stress occurs at the middle of two cracks. With the decreasing distance between the cracks, stress at the middle becomes compressive (Giorgutti-Dauphiné and Pauchard 2016; Bratasz and Vasiri Sereshk 2018; Bai et al. 2000a, b). Bai et al. (2000a) showed that the stress in the direction normal to the developing fracture reached its maximum in the centre of each 'island' for large ratios of spacing between cracks $S$ to fracturing layer thickness $t$, the islands tended to form cracks in the middle. For decreasing $S / t$, the stress dropped to zero and became negative, thus no new crack would ever form. The critical crack spacing calculated theoretically agreed with observations of real paintings (Bratasz et al. 2020). In spite of significant progress in the understanding of crack formation in panel paintings, a gap in knowledge concerning development of two-dimensional 


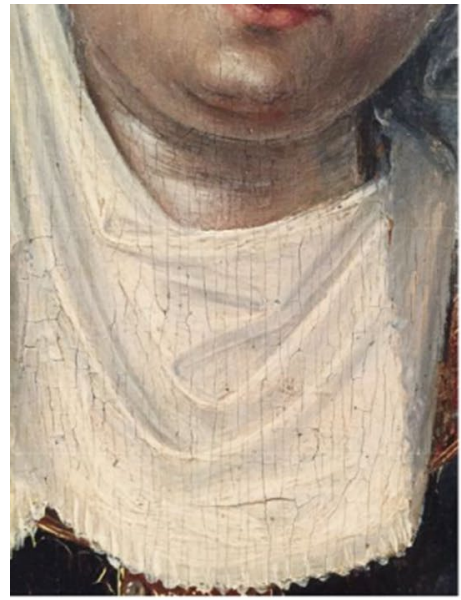

(a)

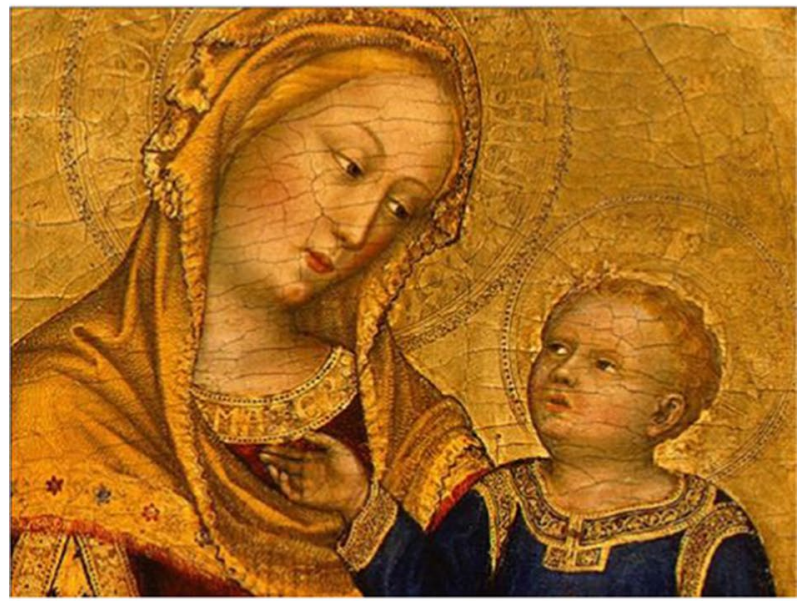

(b)

Fig. 1 Craquelure patterns in historical paintings, a crack pattern parallel to the wood grain in Virgin and Child with St. Anne, Netherlandish school, c. 1495, Yale University Art Gallery, b cracks perpendicular to the wood grain in Madonna and Child Enthroned, c. 1420, Gentile da Fabriano, the National Gallery in Washington

craquelure patterns needs to be addressed. The present paper aims at getting more insight into the role of moisture response of a panel painting and drying shrinkage of the gesso layer in the formation of cracks-along and across the longitudinal wood direction-using analysis of surface stresses in a 3D fully elastic model (understanding how cracks along and perpendicular to the wood grain are formed). In particular, distances between cracks in both tangential and longitudinal directions are estimated. The outcome of the numerical analysis is compared 


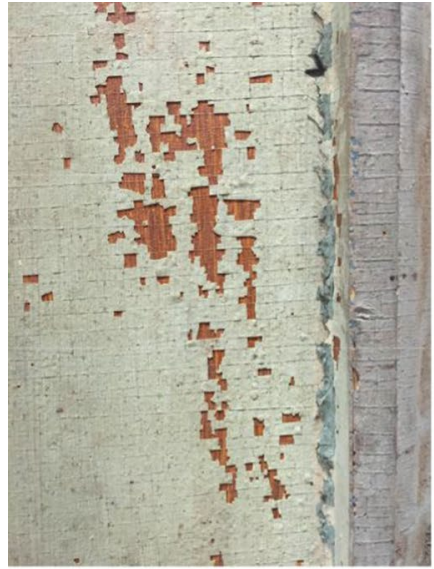

(a)

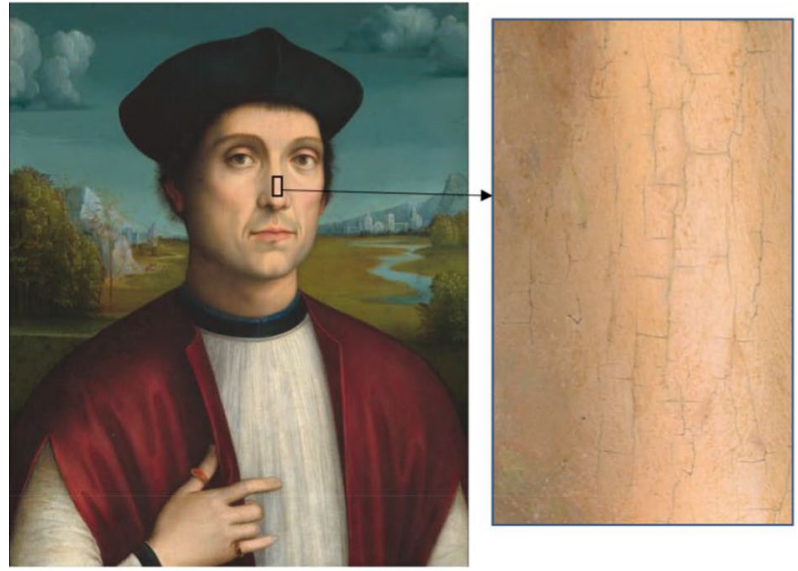

(b)

Fig. 2 Superposition of cracks parallel and perpendicular to the wood grain resulting in square or rectangular craquelure patterns, a an 18th-century decorated wooden element stored in an uncontrolled environment, b Bishop Altobello Averoldo, c. 1505, Francesco Francia, the National Gallery in Washington

with crack patterns obtained experimentally for a mock-up of a panel painting exposed to extreme RH variations in an environmental chamber.

\section{Materials and methods}

\section{Model}

The model of a panel painting shown in Fig. 3 was used initially in this study but was then simplified to one central island to make the parameter study time-efficient. It was assumed that the wooden support was made of lime wood cut in the tangential 
Mode $(1,1)$

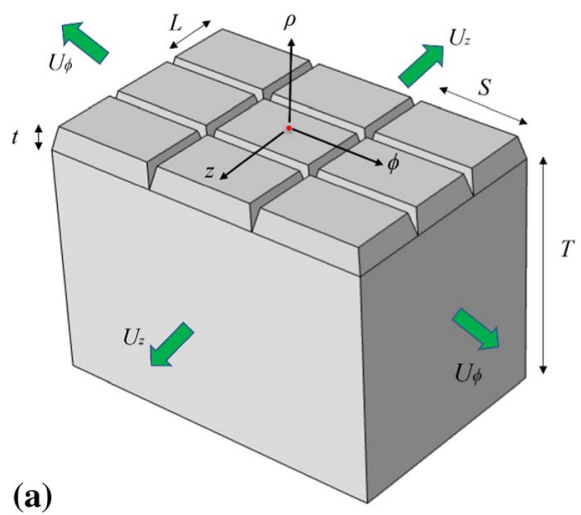

Mode $(1,0)$

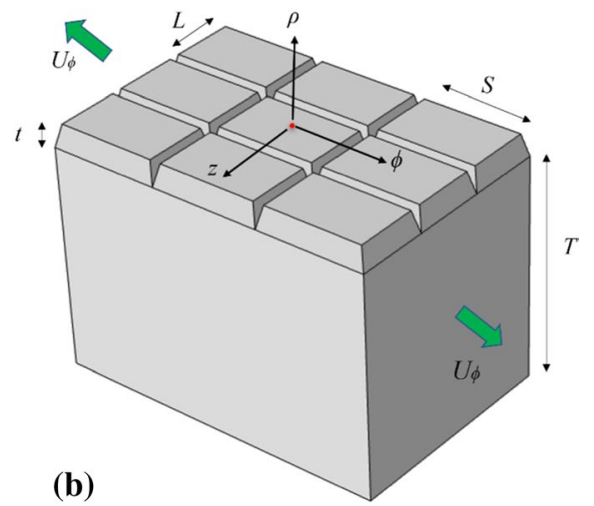

Fig. 3 Conceptual model of a periodic craquelure pattern of rectangular gesso islands on wooden support mimicking a panel painting with cracks perpendicular and parallel to the wood grain. The red dot indicates the point where stresses are largest, and at which the critical stress was calculated. Two loading scenarios detailed in Table 2 are shown: a loading caused by isotropic gesso shrinkage on drying denoted as mode $(1,1)$ which in the model was induced by the equivalent of wood loading $(U z=U \varphi)$, $\mathrm{b}$ uniaxial loading caused by moisture expansion of wood in the tangential direction denoted as mode $(1,0)$

Table 1 Mechanical properties of lime wood and the gesso layer used in the model (Rachwał et al. 2012; Wood handbook 1999)

\begin{tabular}{lll}
\hline Symbol & Value & Units \\
\hline Wood & & \\
$E_{\varphi}$ & $4.80 \times 10^{8}$ & $\mathrm{~Pa}$ \\
$E_{\rho}$ & $8.75 \times 10^{8}$ & $\mathrm{~Pa}$ \\
$E_{z}$ & $1.01 \times 10^{10}$ & $\mathrm{~Pa}$ \\
$G_{\varphi \rho}$ & $2.28 \times 10^{8}$ & $\mathrm{~Pa}$ \\
$G_{z \rho}$ & $5.66 \times 10^{8}$ & $\mathrm{~Pa}$ \\
$G_{z \varphi}$ & $4.65 \times 10^{8}$ & $\mathrm{~Pa}$ \\
$v_{\varphi \rho}$ & 0.346 & - \\
$v_{\rho z}$ & 0.034 & - \\
$v_{\varphi z}$ & 0.022 & - \\
$G \mathrm{esso}$ & & \\
$\mathrm{E}_{\mathrm{g}}$ & $3.75 \times 10^{9}$ & $\mathrm{~Pa}$ \\
$v_{\mathrm{g}}$ & 0.2 & - \\
\hline
\end{tabular}

direction and its thickness $T$ was $40 \mathrm{~mm}$. The thickness of the gesso layer $t$ was 2 $\mathrm{mm}$. The width of the crack was $10 \mu \mathrm{m}$. The mechanical properties of the two components are detailed in Table 1 . Wood in the direction along the fibres ( $z$-component) is significantly stiffer than in the radial ( $\rho$-component) and tangential ( $\varphi$-component) directions. In contrast to the stiffness, moisture expansion in the $\varphi$ - or $\rho$-directions is significantly larger than in the $z$-direction, which can be considered as dimensionally stable. 
Two different boundary displacements were studied. The boundary displacement of side walls of the panel in the $\varphi$-direction, corresponding to swelling of the panel due to an increase in $\mathrm{RH}$, is shown in Fig. 3a, and the boundary displacements of side-walls of the panel in the $\varphi$ and $z$-directions, corresponding to the isotropic drying shrinkage of the gesso layer, are shown in Fig. 3b. In both cases, the applied displacements were such that strains $\varepsilon_{0}$ in the $\varphi$ - and $z$-directions were $1 \%$. The summary of the applied displacements is given in Table 2. The external load was used instead of a hygroscopic strain as the aim of this research was to analyse solely the effect of full moisture-related expansion of flat wood support as the worst case condition that leads to gesso cracking. Therefore, cupping concave to the painted face, encountered in panel paintings, was not considered as it reduces the damaging impact of wood's expansion on the gesso layer. The model with the external loads also required much less computational time. Further, critical stress was calculated for a point at the gesso surface where stresses were largest - the origin of the coordinate system (Fig. 3). Bratasz et al. (2020) showed that cracks would develop starting from the surface rather than sub-surface flaws even for maximum flaw dimensions observed in historical paintings using X-ray computer microtomography. The central point at the surface was blocked in movement $\left(U_{z}=U_{\varphi}=U_{\rho}=0\right)$, the corresponding point at the bottom of the panel was blocked in the $z$ - and $\varphi$-directions $\left(U_{z}=U_{\varphi}\right.$ $=0)$ and the projection of the latter in the $z$-direction on the side-wall was blocked in the $z$-direction $\left(U_{z}=0\right)$. All other surfaces, including the top and the bottom of the structure, and gesso layer sides were wholly unrestrained. For this two-layer model, it was postulated that the two materials were fully kinematically constrained at the interface, i.e., no slip or opening was permitted along the interface. Moreover, any initial cupping of a panel was neglected.

A self-adaptive finite element mesh was used during simulations with a total number of computational nodes not smaller than one million, and a finer mesh in the central and neighbouring gesso islands.

Free triangular controlled extremely fine mesh patterns were used to discretize object geometry in solid mechanics module of COMSOL including geometry nonlinearity for the study. In case of the simplified 3D model, the number of domain elements was reduced by a factor of 4 , and the numbers of boundary and edge elements were reduced by a factor of 2 , but the number of domain elements still was approximately 1 million. The generalization of critical crack

Table 2 Two loading scenarios used in the model

\begin{tabular}{lllll}
\hline Mechanism & $\begin{array}{l}\text { Strain in the } \\
\varphi \text {-direction }\end{array}$ & $\begin{array}{l}\text { Strain } \\
\text { in the } \\
z \text {-direction }\end{array}$ & Source & Mode $(\varphi, z)$ \\
\hline Moisture response of wood & 0.01 & 0 & $\begin{array}{l}\text { Expansion of wooden support } \\
\text { in the tangential direction on } \\
\text { an increase in RH }\end{array}$ \\
Drying shrinkage of the gesso & 0.01 & 0.01 & $\begin{array}{l}\text { Drying shrinkage of the gesso } \\
\text { layer }\end{array}$ & $(1,1)$ \\
\hline
\end{tabular}


saturation distance defined by Bai et al. (2000a) to a 3D case with a rectangular crack pattern is straightforward. Next to the $S / t$ ratio in the tangential direction, a new parameter-the $L / t$ ratio-was defined in the longitudinal direction where $S$ and $L$ were spacings between cracks in the two directions, respectively (Fig. 3). In both cases, no new edge cracks perpendicular to the $\varphi$ - and $z$-directions can develop starting from the surface, if the stresses in the $\varphi$ - and $z$-directions $-\sigma_{\varphi}$ and $\sigma_{z}$-drop below zero, i.e. become compressive, respectively. The critical values of $S / t$ and $L / t$ are defined by conditions $\sigma_{\varphi}=0$ and $\sigma_{z}=0$ in the point of stress calculation.

\section{Mathematical modelling}

Based on fracture saturation theory (Bratasz et al. 2020), the critical condition of the system is when the tangential component of stress in the middle point of the top surface $\sigma_{\varphi}$ changes its sign

$$
\sigma_{\varphi}=0
$$

To calculate the stress field inside the computational domain, the elasticity equation was applied to an anisotropic solid material, with the static equilibrium equation:

$$
\nabla \vec{\sigma}=0
$$

where $\nabla$ is the divergence vector and $\sigma$ is the stress components' vector. The static equilibrium equation is derived from balance of all forces that act upon a differential volume. The partial differential equation weak form requires three dependent variables $u ; v ; w$ to represent the displacement vector $\boldsymbol{U}=[u ; v ; w]$. The strain $\vec{\varepsilon}$ is defined as

$$
\vec{\varepsilon}=\frac{\nabla \boldsymbol{U}+\nabla^{T} \boldsymbol{U}}{2}
$$

where $\nabla^{T}$ is the transpose of the gradient vector. In the general case of linear elastic materials, the material properties have a directional sensitivity. The most general case is called anisotropic, for which all six stress components can depend on all six strain components. This requires 21 material parameters. The stress component vector $\boldsymbol{\sigma}$ in Eq. 2

$$
\vec{\sigma}=\left[\begin{array}{c}
\sigma_{\varphi} \\
\sigma_{\rho} \\
\sigma_{z} \\
\sigma_{\varphi \rho} \\
\sigma_{z \rho} \\
\sigma_{z \varphi}
\end{array}\right]
$$

and strain $\boldsymbol{\varepsilon}$ 


$$
\vec{\varepsilon}=\left[\begin{array}{c}
\epsilon_{\varphi} \\
\epsilon_{\rho} \\
\epsilon_{z} \\
\epsilon_{\varphi \rho} \\
\epsilon_{z \rho} \\
\epsilon_{z \varphi}
\end{array}\right]
$$

are related by the anisotropy constitutive 6-by-6 symmetric compliance matrix $\underline{C}$, through

$$
\vec{\varepsilon}=\underline{C} \vec{\sigma}
$$

where the symmetric compliance matrix in the case of orthotropic material (the twelve constants used are reduced to nine) is

$$
\underline{C}=\left[\begin{array}{cccccc}
\frac{1}{E_{\varphi}} & \frac{-v_{\rho \varphi}}{E_{\rho}} & \frac{-v_{z \varphi}}{E_{z}} & 0 & 0 & 0 \\
\frac{-v_{\varphi \rho}}{E_{\varphi}} & \frac{1}{E_{\rho}} & \frac{-v_{z \rho}}{E_{z}} & 0 & 0 & 0 \\
\frac{-v_{\varphi z}}{E_{\varphi}} & \frac{-v_{\rho z}}{E_{\rho}} & \frac{1}{E_{z}} & 0 & 0 & 0 \\
0 & 0 & 0 & \frac{1}{G_{\rho z}} & 0 & 0 \\
0 & 0 & 0 & 0 & \frac{1}{G_{\varphi z}} & 0 \\
0 & 0 & 0 & 0 & 0 & \frac{1}{G_{\varphi \rho}}
\end{array}\right]
$$

In the above equations, $E_{i j}$ is the elasticity modulus ( $i$ and $j$ are indexes for directions), $v_{i j}$ is the Poisson's ratio, and $G_{i j}$ is the shear modulus related to the material.

\section{Preparation of a mock-up and experimental procedure}

A wooden panel of dimensions $210 \mathrm{~mm}$ x $290 \mathrm{~mm}$ x $40 \mathrm{~mm}$ was cut from a lime wood trunk seasoned for several years in dry conditions. The orientation of the panel was predominantly radial except for a central tangential section. The panel was sized with a $(1: 10 \mathrm{w} / \mathrm{w})$ solution obtained by dissolving rabbit skin glue (Kremer Pigmente $\mathrm{GmbH}$ ) in water at a temperature of $60{ }^{\circ} \mathrm{C}$. Glue was applied with a brush when glue solution was still warm (ca. $45^{\circ} \mathrm{C}$ ). The sized panel was gessoed with the chalk-glue ground of pigment volume concentration $\mathrm{PVC}$ of $92 \%, \mathrm{PVC}=$ $P /(P+B)$ where $P$ and $B$ were volumes of the pigment (chalk) and the dried glue binder, respectively. A solution $(1: 14 \mathrm{w} / \mathrm{w})$ obtained by dissolving rabbit skin glue in water at a temperature of $60{ }^{\circ} \mathrm{C}$ was used to prepare gesso of determined PVC. Chalk was then slowly added to the glue solution until no liquid was visible. The gesso preparation procedure was adopted after a historical recipe in the treatise of the early $15^{\text {th }}$ century authored by Cennino Cennini (Cennini 1972). The thickness of the gesso layer applied by a brush was approximately $1.6 \pm 0.1 \mathrm{~mm}$. The mockup painting was equilibrated at room temperature and $\mathrm{RH}$ of approximately $50 \%$ for four weeks. After curing, all side edges were sealed with aluminium sticky foil to block moisture transport from the sides of the painting. 
The specimen was exposed to extreme RH cycles 10-90-10\% in an environmental chamber until no further crack development was observed. The temperature during the experiment was elevated to $40{ }^{\circ} \mathrm{C}$ to speed up moisture transport to and from the specimen. The response time of a wooden panel of a thickness of $40 \mathrm{~mm}$ is approximately 1-3 months at room temperature, unacceptably long for the experiment. By weighing the specimen, it was estimated that 10 days at $40{ }^{\circ} \mathrm{C}$ were sufficient for the panel equilibration. After the experiment, the surface of gesso layer was photographed.

\section{Analysis of craquelure patterns}

The crack detection was based on the fact that crack lines were darker than a homogeneous, bright background of the recorded image. The analysis was performed in several steps using built-in functions offered in Wolfram Mathematica software. The selection of morphological operators as well as the sequence in their application was based on a try and error procedure. The major steps included:

\section{- Crack identification}

Basic morphological operators such as conversion to a grayscale image, convoluted erosion and dilation were used to make cracks more visible and to remove close loop imperfections in crack topography like particles, so that only substantive components remain. Next, more complex morphological operations were used like top-hat closing to extract dark features or Toggle Tapping (TM). The TM allows for contrast enhancement and noise reduction by segmentation of the grayscale image according to the pixel intensity. This is carried out by introducing two operators that distinguish intensity (maxima and minima) and create homogenous local regions. Next, the thinning and binarization operators were implemented to obtain the skeleton of crack pattern for the recorded image. The operation involves removing neighbouring pixels leaving only central, pixel wide crack lines.

\section{- Transformation of a craquelure pattern into a set of lines}

This step involves the implementation of Range Filter (RF) which filters data by maxima and minima in the specified neighbour range $r F$. First, the RF allows junctions of the skeletonized image to be detected. Second, RF's output is a function of a local pixel arrangement that allows the junction type, its position and line directions to be specified. Hence, the graph indexed by the vertices and edges that corresponded to the craquelure pattern of the analysed image was obtained. $r F$ is a free parameter that is selected to obtain the best fit of the craquelure pattern to the original image. The lower $r F$, the more detailed but noisy the pattern becomes. In turn, higher $r F$ results in missing out certain cracks, which implies a loss of data. $r F$ of 0.025 was chosen. Such a choice gave an optimal recognition of the analysed crack pattern. The vertices and edges were joined to represent cracks by straight 
lines rather than line paths. In this way, single lines representing edges of the islands in the craquelure pattern in the image were extracted.

- Statistical evaluation of lines

A set of lines representing a craquelure pattern was categorized into two groups of cracks-parallel and perpendicular to the wood grain assuming that they should deviate from each direction by less than 45 degrees. For each category of lines, their mean length was calculated which can be interpreted as mean distance between the cracks in the respective directions for the rectangular crack representation. The three steps of analysis of craquelure patterns described above are presented in Fig. 4.

\section{Results and discussion}

\section{Simplification of the model}

The initial model was simplified to one central island marked with the red dot in Fig. 3. To estimate the error caused by such simplification, stress distribution at the surface of the central island was calculated when further islands (one, two, or three) were added in the model at each side of the central island along the $\varphi$-direction of loading. One quarter of each configuration was used in the modelling as two symmetry conditions along the $\mathrm{z}$ - and $\varphi$-directions were applied in the centre of the model (Fig. 5a). Differences between results obtained using the 3D models with various numbers of gesso islands are presented in Fig. $5 b$ for the case of loading mode $(1,0)$. As can be seen, the difference introduced by reducing the size of the model from seven to three islands is approximately $2 \%$ and grows to about $10 \%$ in the case of one gesso island. Such difference is acceptable in this study aimed at explaining the general mechanism of crack formation. Figure $5 \mathrm{c}$ shows that the normalized stress component in the $\varphi$-direction linearly increases with the normalized distance from the top of the gesso island downwards.

The results of the $3 \mathrm{D}$ modelling were compared with predictions obtained using a 2D model developed by Bratasz et al. (2020). A comparison of the

(a)

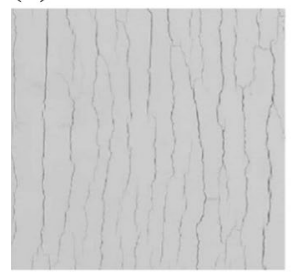

(b)

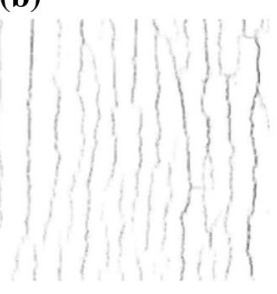

(c)

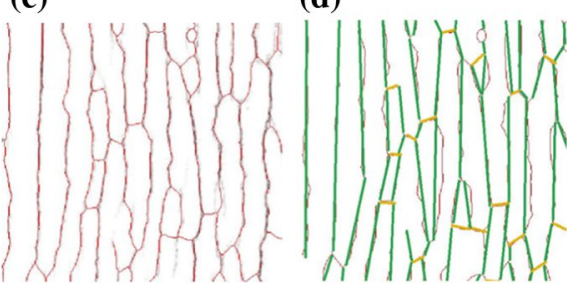

Fig. 4 Visualization of steps in the analysis of a craquelure pattern, a grayscale of the original mockup image, b image after morphological operations described in the crack identification step, $\mathbf{c}$ extracted craquelure pattern obtained in the second step of the process, $\mathbf{d}$ categorization of extracted lines into directions parallel (green) and perpendicular (orange) to the wood grain 

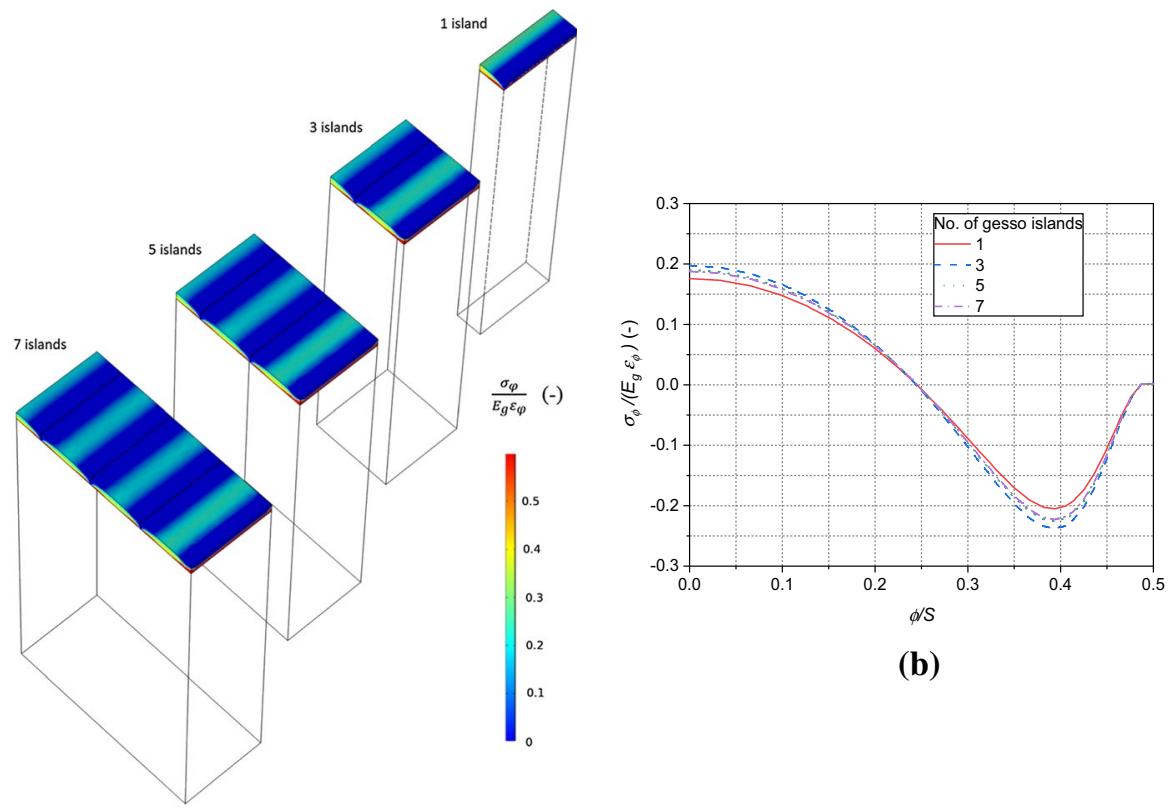

(b)

(a)

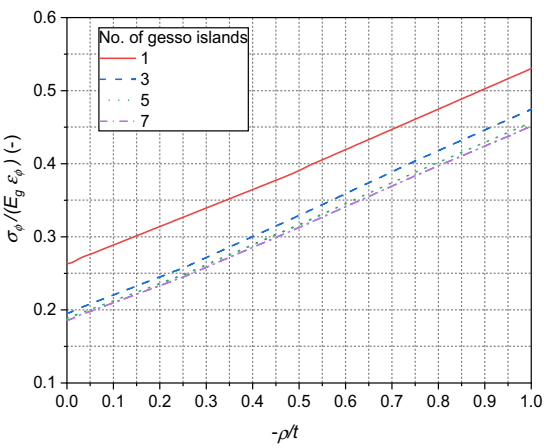

(c)

Fig. 5 Impact of model simplification on the normalized tangential stress distribution at the surface, a general geometry for models with various numbers of gesso islands, the colour scale indicates the normalized stress component in the $\varphi$-direction in the central gesso island, $\mathbf{b}$ the same quantity as a function of the normalized distance from the centre of the gesso island in the tangential direction of the wood support, $\mathrm{c}$ the same quantity as a function of the normalized distance from the top of the gesso island downwards

$\varphi$-component of top surface stress obtained in the 2D and 3D cases is shown in Fig. 6 for the $S / t$ ratio of 5.65 and loading mode $(1,0)$. It can be seen that both stress distributions are in good agreement. The slight discrepancies between the two models can be explained by a difference in the mesh density, which was much smaller in the $3 \mathrm{D}$ case compared to $2 \mathrm{D}$. 


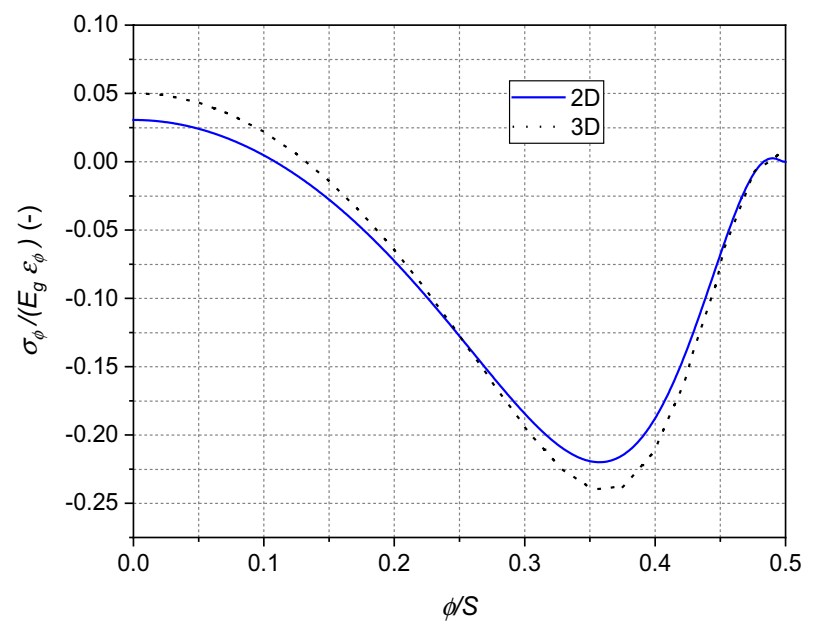

Fig. 6 Comparison of the stress component in the $\varphi$-direction of stress field on the surface obtained with 3D modelling for the case of loading mode $(1,0)$ with the results obtained by Bratasz et al. (2020). In both cases, the $S / t$ ratio was 5.65 , and $L / t$ was 10 in the $3 \mathrm{D}$ model

\section{Stress distribution for the tangential loading}

The optimized model was used to perform a parameter study by changing $L / t$ and $S / t$ in the case of stresses engendered in the gesso layer by wood swelling in the tangential direction on increasing RH-the mode $(1,0)$ loading shown in Fig. 3a. Figure 7 shows plots of the normalized $\varphi$-component of stress field in the point of stress calculation as a function of $S / t$ and for various $L / t$ ratios. The stress component was

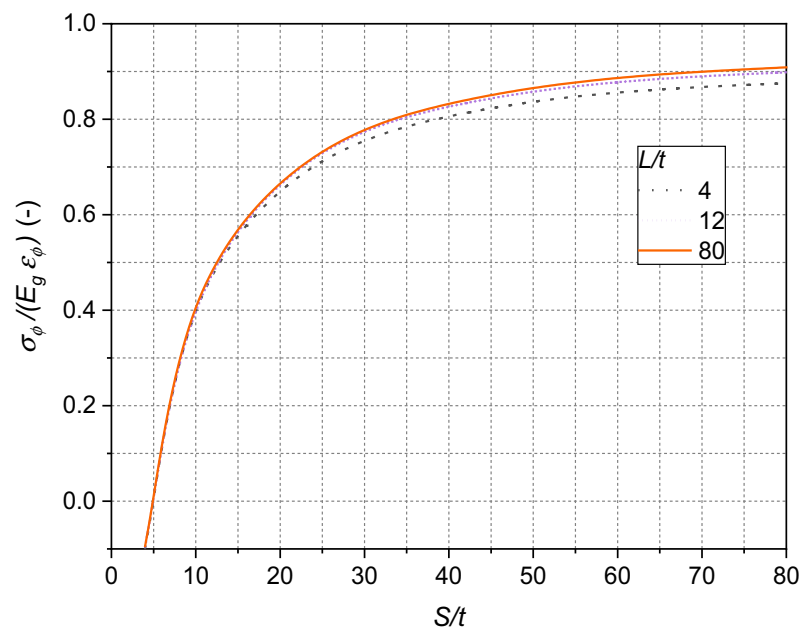

Fig. 7 Normalized stress in the $\varphi$-direction in the point of stress calculation as a function of $S / t$ for various $L / t$ ratios 
normalized to the stress in the gesso layer without cracks and the applied strain was $0.01\left(\sigma_{0}=E_{g} \times \varepsilon_{0}=3.75 \mathrm{GPa} \times 0.01=3.75 \times 10^{7} \mathrm{~Pa}\right)$. The normalized stress asymptotically reaches 1 for large $S / t$ ratios and slowly decreases with decreasing $S / t$ until about 10. A further decrease of $S / t$ causes a rapid decrease of the normalized $\varphi$-component of stress. For the critical $S / t$ value of 4.6 , the normalized $\varphi$-component drops to zero and further cracks in the direction perpendicular to the $\varphi$-direction cannot be initiated at the surface irrespective of the applied loading induced by swelling of wood. The model prediction is not dependent on the properties of the gesso layer-neither fracture tightness nor strength. Therefore, the outcome of the modelling is universal. The dynamics of crack pattern development (initiation of cracking, the critical stress value and the magnitude of $\mathrm{RH}$ change inducing it) was not within the scope of this paper. The critical value of 4.8 obtained with $2 \mathrm{D}$ modelling was almost identical (Bratasz et al. 2020). In both models, the critical $S / t$ ratio increases with an increasing ratio of gesso-to-wood stiffness. For stiffness of gesso of 10,1 and $0.1 \mathrm{GPa}$ and wood parameters as in Table 2, the critical $S / t$ ratios are 6 , 3.2 and 2.4 , respectively, and the $L / t$ ratio is 40 .

Interestingly, the value of the $\varphi$-component of stress does not depend on the distance between cracks in the $z$-direction. This means that development of cracks in the $\varphi$-direction does not influence development of cracks in the $z$-direction. In the case of radially cut panels, the critical $S / t$ ratio is slightly larger than for tangentially cut panels (Fig. 7) and is 5.2 (not shown).

The same loading applied in the $\varphi$-direction includes a nonzero $L$-component of the stress, except for certain combinations of $S / t$ and critical $L / t$ ratios, as shown in Fig. 8. For large $L / t$ and $S / t$, the normalized $z$-component of stress asymptotically reaches the maximum value of 0.15 and drops gradually to negative values for decreasing $L / t$, if $S / t$ is constant. The $z$-component also decreases for decreasing $S / t$ ratio. If $S /$ is smaller than 4.6 , the $\varphi$-component is negative, independent of the $L / t$ ratio.

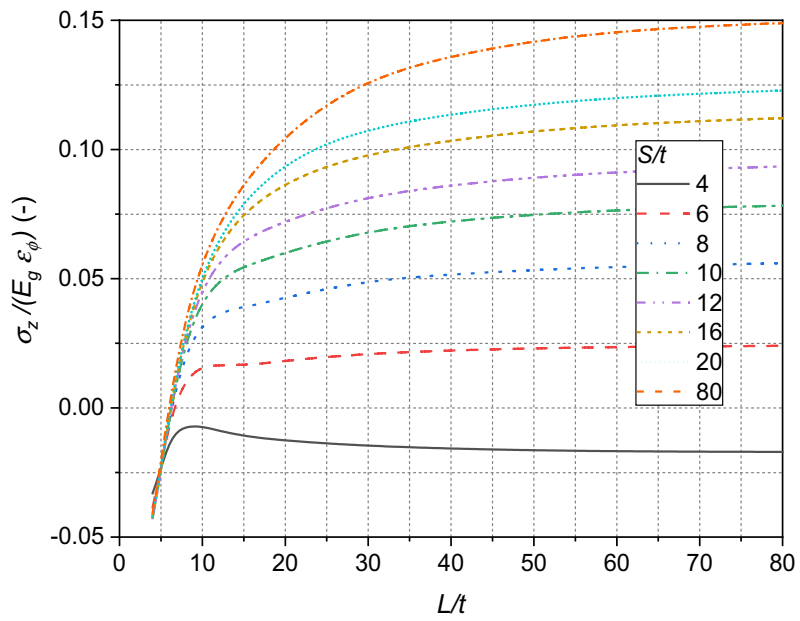

Fig. 8 Normalized stress in the z-direction in the point of stress calculation as a function of $L / t$ 
The above results indicate that moisture response of wood in the tangential direction cannot cause cracking of gesso across the grain in spite of a nonzero $z$-component of stress due to Poisson's effect. This is because the $\varphi$-component is always greater than the $z$-component. Moreover, analysis of total elastic energy stored in the system (Fig. 9d) indicates that it is more beneficial for the system to densify cracks along the grain, not across.

Albeit the presented results are based on the elastic model, some information on fracture of a ductile material can be gathered using analysis of von Mises stress. The maximum distortion criterion (von Mises yield criterion) assumes that yielding of a ductile material begins when the second invariant of deviatoric stress reaches a critical value. The assumption is part of the plasticity theory that applies best to ductile materials, such as gesso at high RH levels. Figure 9c shows a map of von Mises stress as a function of the $S / t$ and $L / t$ ratios. Further, when analysing von Mises stress, one can see that cracks form in the direction parallel to the grain, not across.

\section{Stress distribution due to drying shrinkage}

Drying shrinkage of gesso is another mechanism leading to its cracking. Tensile stresses were modelled by applying the mode $(1,1)$ loading shown in Fig. 3b with a strain of 0.01 in both directions. Figures 10 and 11 show the normalized $\varphi$ - and $z$-components of stress field, respectively, in the point of stress calculation as a function of $S / t$ and for various $L / t$ ratios. The stress component was normalized as described in the previous section.

It can be seen that the normalized $\varphi$-component of stress in the point of stress calculation exhibits a similar dependence on the $S / t$ ratio as in the case of the tangential loading, with maximum stress being the same for $L / t$ ratios smaller

(a)

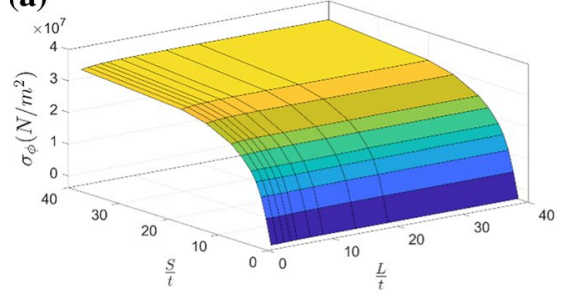

(c)

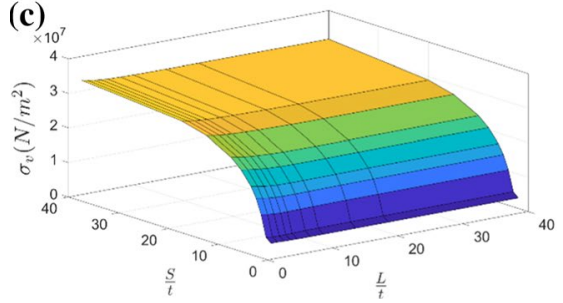

(b)

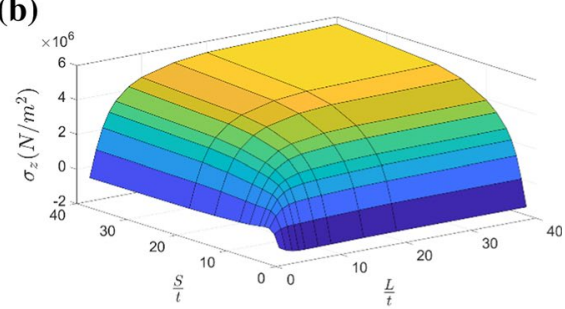

(d)

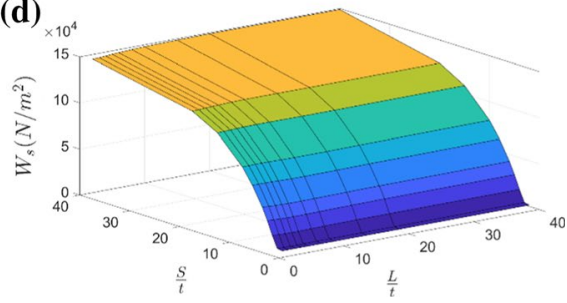

Fig. 9 a $\varphi$-component of stress, $\mathbf{b} z$-component of stress, $\mathbf{c}$ von-Mises stress and $\mathbf{d}$ elastic energy in the critical point as a function of $L / t$ and $S / t$ 


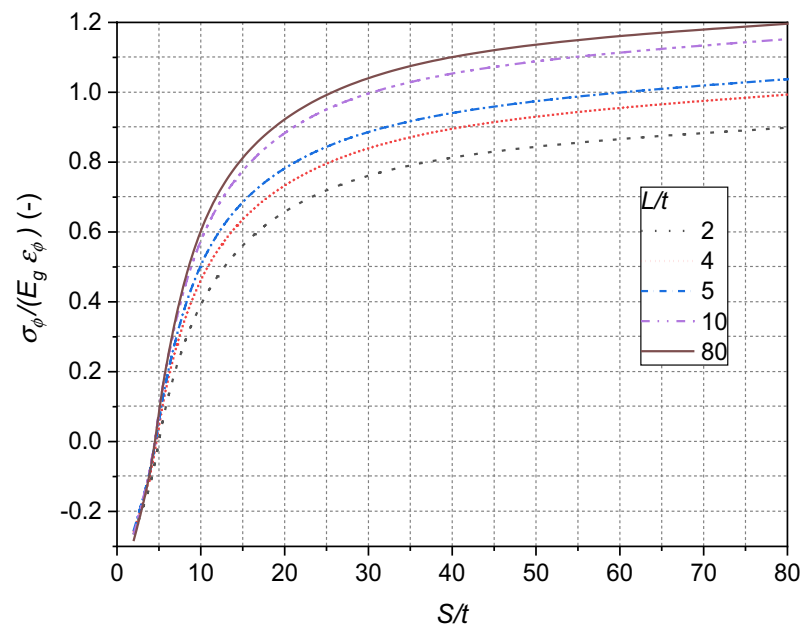

Fig. 10 Normalized $\varphi$-component of stress in the point of stress calculation as a function of $S / t$ for various $L / t$ ratios and loading mode $(1,1)$

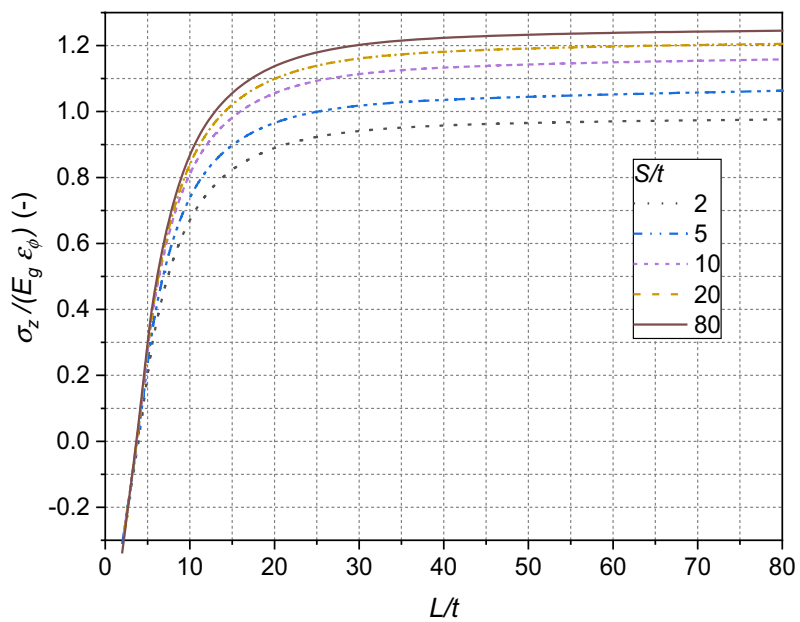

Fig. 11 Normalized z-component of stress in the point of stress calculation as a function of $L / t$ for various $S / t$ ratios and loading mode $(1,1)$

than 5 and about $30 \%$ higher for large $L / t$ ratios. Analogously, the normalized $z$-component of stress in the point of stress calculation is 0.9 for $S / t$ ratio of 2 and approaches asymptotically 1.2 for large $S / t$ ratios. The increase of maximum $\varphi$ - and $z$-components of stress is due to the impact of Poisson's ratio when the biaxial loading is applied, not observed under only tangential loading.

The critical $S / t$ and $L / t$ ratios range between 4.5 and 5 , and 3.5 and 4 , respectively, depending on the $L / t$ and $S / t$ ratios. This is surprising, as the prediction of the $2 \mathrm{D}$ model would suggest that the critical $L / t$ ratio is much smaller, about 
2.5, as the ratio of gesso-to-wood stiffness in the longitudinal direction is 0.37 (Bratasz et al. 2020).

\section{Stress distribution in the mixed mode}

Figure 12 shows diagrams that illustrate the effect of superposition of various modes of loading on evaluated strains. As the diagrams demonstrate just patterns of strain variations under diverse environmental scenarios, moisture sorption was not considered in detail and simple relationship between moisture-related strain and relative humidity was assumed without considering the hysteresis. As plotted in Fig. 12b, the $\varphi$-component of moisture-related strain of wood (blue line) is proportional to an $\mathrm{RH}$ variation around mean $\mathrm{RH}$ (Fig. 12a). The z-component of the moisture-related strain is negligible (dotted red line). Moreover, the moisture-related strain in the gesso is negligible in both directions. The drying shrinkage of gesso causes negative strain in all directions (orange dashed line). If the gesso has ideally adhered to a wooden support, elastic strain develops in the gesso as shown in Figs. 12c (without drying shrinkage) and $12 \mathrm{~d}$ (with drying shrinkage).

Elastic strain distribution in Fig. 12c corresponds to the uniaxial mode resulting from the panel's moisture response. However, in most practical situations,
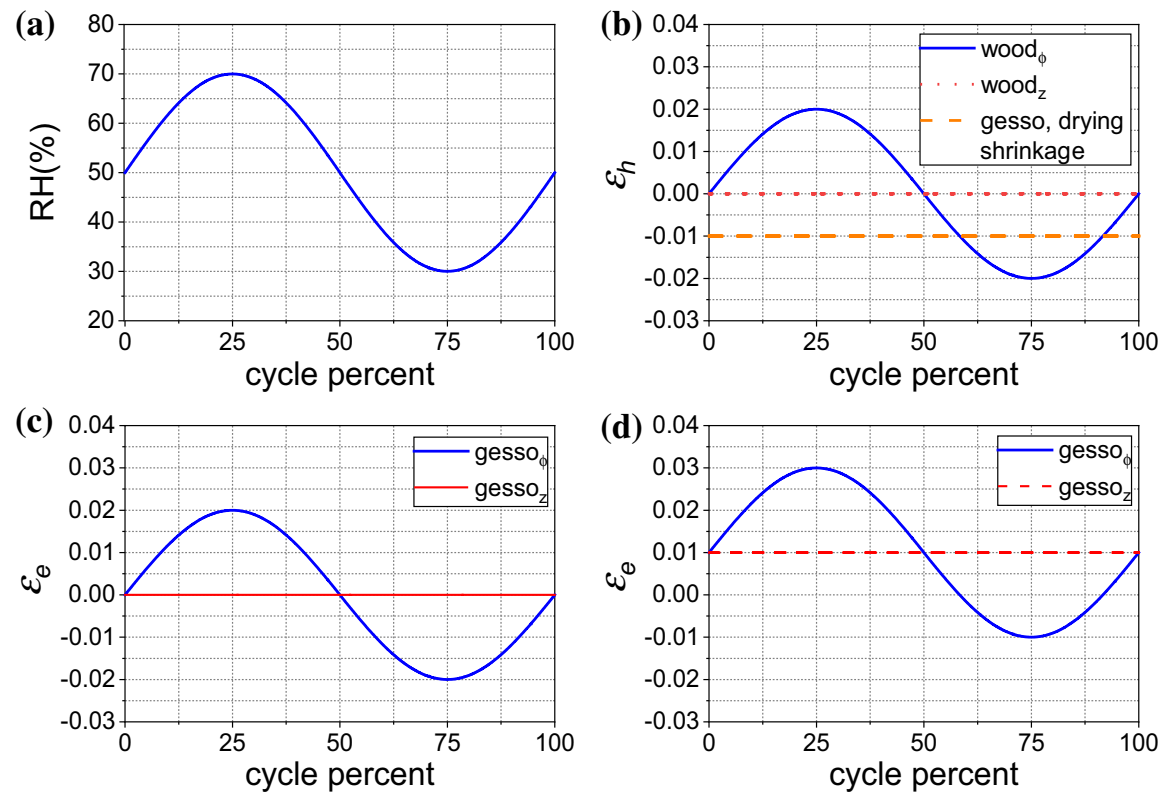

Fig. 12 Various strain versus time histories induced by an $\mathrm{RH}$ variation and drying shrinkage of the gesso, a RH variation, $\mathbf{b}$ moisture-related strain $\left(\varepsilon_{\mathrm{h}}\right)$ induced in freely responding wood and gesso by the RH variation and drying shrinkage, respectively, c elastic strains engendered in the gesso layer due to the moisture response of wood-loading mode $(1,0)$, $\mathbf{d}$ elastic strains engendered in the gesso layer due to moisture response of wood and drying shrinkage of the gesso-loading mode $(3,1)$ 
paint layers in panel paintings experience mixed mode situations when stresses induced by drying shrinkage of the gesso superimpose with stresses induced by moisture response of the wooden support. In consequence, maximum $\varphi$-component of elastic strains in the gesso is larger than the $z$-component of strain field. This situation is represented in Fig. 12d and, at a quarter of the cycle, corresponds to mixed mode $(3,1)$ - the $\varphi$-component of stress is 3 times larger than the $z$-component. Obviously, the moisture-related strain of the panel at the beginning, the mid-point and the end of the cycle is zero, therefore, the gesso layer experiences the mode $(1,1)$ loading resulting from drying shrinkage only.

The ratio of critical distance $L$ between cracks in the $z$-direction to critical distance $S$ between cracks in the $\varphi$-direction is shown in Fig. 13 as a function of the ratio of $\varphi$ - and $z$-components of strain. It was assumed that this strain ratio could not be larger than 1 as maximum $\varphi$-component of strain in the fully elastic model is always larger than the maximum $z$-component. The critical $L / S$ ratio varies between 0.8 and 1.7 for all strain ratios. In consequence, one can expect larger distances between cracks across than along the grain in panel paintings. As demonstrated in the previous section, although the critical $L / S$ ratio approaches 1.7 for decreasing strain ratio, no cracks are formed across the grain, if loading is applied only in the $\varphi$-direction. Therefore, one can expect that the $L / S$ value in panel paintings is large or infinite if there is no drying shrinkage of gesso or other isotropic shrinkage of the paint layer. These results help to analyse and interpret craquelure patterns observed in panel paintings, in particular those represented in Figs. 1a and 2. However, the presented model does not explain how cracks represented in Fig. 1b have developed.

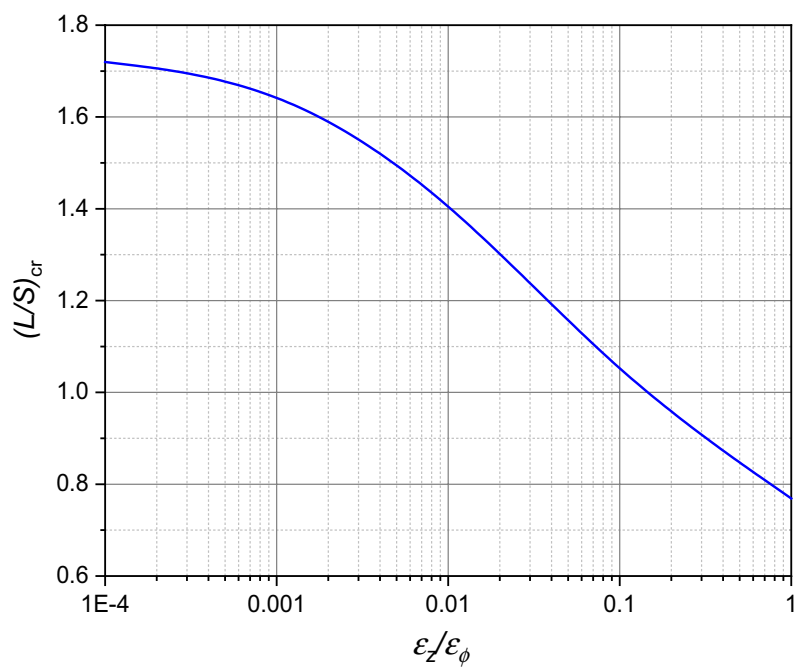

Fig. 13 Critical L/S ratio as a function of applied strain ratio 


\section{Experimental results}

Results of the computer simulations presented above were compared with craquelure patterns induced in the mock-up panel painting by $20 \mathrm{RH}$ cycles in the range $10-90-10 \%$. After a few RH cycles, the gesso layer was covered with a dense network of cracks, which stabilized after approximately 15 cycles, so no further crack development was observed in the last five cycles. The recorded image was evaluated using the procedure described in the section on analysis of craquelure patterns. Figure 14 illustrates major steps of the analysis. It was found that, for $\alpha=10^{\circ}, 75 \%$ of all line lengths were included in the analysis increasing to $91 \%$ for $\alpha=20^{\circ}$. A further increase of $\alpha$ resulted in a slow increase to $100 \%$ for $\alpha=45^{\circ}$. The observations indicate that most of the lines are approximately parallel or perpendicular to the wood grain. Finally, $\alpha=20^{\circ}$ was selected to calculate the mean distance between cracks in the mock-up painting.

It was found that mean distances between cracks perpendicular and parallel to the wood grain were $18 \pm 3 \mathrm{~mm}$ and $3.2 \pm 0.1 \mathrm{~mm}$, respectively. Taking into account the average gesso thickness of $1.6 \mathrm{~mm}$, one can find that the $S / t$ ratio is 2 and the $L / t$ ratio is 11 . The $L / S$ ratio is about 6 . The $S / t$ value of 2 agrees well with the value 2.4 determined for the gesso of stiffness of $0.1 \mathrm{GPa}$ with the $3 \mathrm{D}$ modelling and the tangential loading presented in this work. The $S / t$ value tends to be up to $20 \%$ smaller in loading mode $(1,1)$. Although any precise comparison of $S / t$ and $L / t$ ratios determined experimentally and theoretically is difficult as stiffness of gesso significantly decreases with an increasing $\mathrm{RH}$ reaching value of $0.1 \mathrm{GPa}$ above $90 \%$ RH (Krzemień et al. 2016) and further decreases with increasing $T$, it can be concluded that both approaches resulted in similar values. In consequence, despite the high anisotropy of the support, the crack development would be almost isotropic. It was just assumed that both stresses induced by moisture-related response of the wood and caused by drying shrinkage of the gesso are much higher than critical stress. The similarity in the $S / t$ ratio indicated that extensive RH variations caused
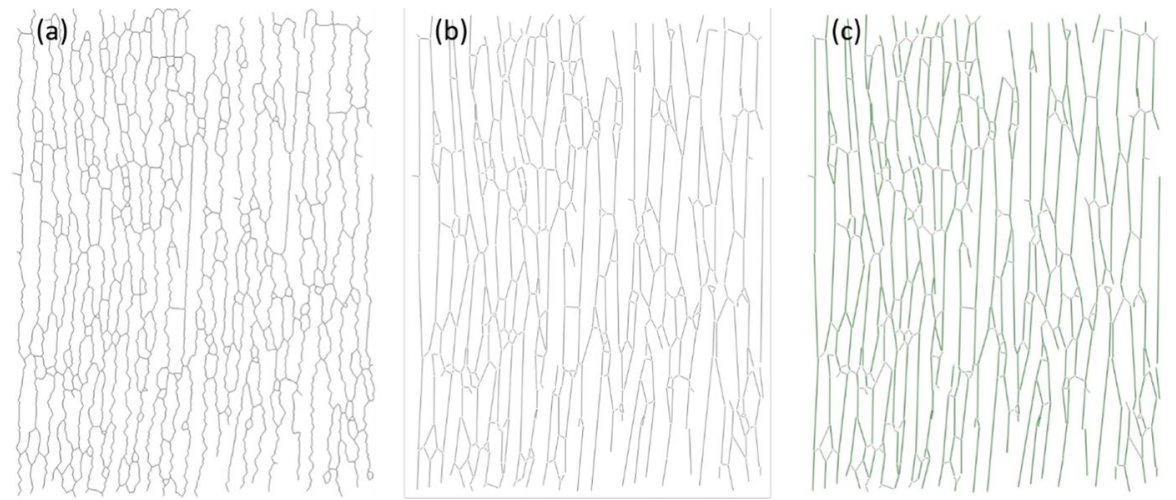

Fig. 14 Illustration of major steps in statistical analysis of crack patterns, a crack identification, $\mathbf{b}$ transformation of a craquelure pattern into a set of lines, $\mathbf{c}$ statistical evaluation of lines for $\alpha=20^{\circ}$, green colour indicates lines selected for the analysis and grey colour shows lines omitted 
significant loads in the direction parallel to the wood grain in the mock-up painting. The formation of cracks in the direction perpendicular to the wood grain indicated that drying shrinkage of the gesso layer also occurred so the specimen was subjected to the mixed mode loading. The $L / t$ ratio of 11 suggested that stresses generated due to drying shrinkage were lower than stresses leading to crack saturation in the direction perpendicular to the wood grain.

\section{Conclusion}

In the current study, a three-dimensional structural model of a cracked panel painting was developed for the first time to simulate stress fields in the gesso layer. The model was used to analyse two loading modes-moisture response of a wooden panel and drying shrinkage of gesso-as well as their superposition. The resulting stress fields shed light on processes leading to the formation of typical crack patterns found in panel paintings - parallel or perpendicular to the wood grain, and rectangular. It was found that moisture related expansion of wood explained the formation of cracks along the grain but could not explain the formation of cracks across the grain. The critical crack distance normalized to the gesso thickness for moisture response of a tangentially cut wooden panel was between 6 and 2.4 depending on gesso stiffness. For the radial cut, this value was about $10 \%$ higher.

The isotropic drying shrinkage of gesso produced almost square cracks of aspect ratio $4: 5$ in the tangential to longitudinal directions. The critical $S / t$ and $L / t$ ratios ranged between 4.5 and 5 , and 3.5 and 4 , respectively.

Despite the usefulness of the 3D model developed, it cannot explain how patterns with cracks only perpendicular to the wood grain or patterns in which cracks perpendicular to the grain are much denser than cracks parallel to the grain, are formed. The potential explanation could be related to plastic deformation of wooden support frequently leading to warping of panel paintings, which reduces the tangential loading and, in consequence, makes the z-component of strain a more probable cause of fracturing perpendicular to the wood grain.

The outcome of the 3D modelling and the experimental results confirm our earlier conclusions that paintings, after reaching a certain level of crack density, are much less vulnerable to increases in RH leading to tensile stresses I in the paint layer. Further steps need to consider the multi-layer structure of the paint layer as well as the presence of defects that can initiate cracks below the surface.

Acknowledgements The authors gratefully acknowledge help of professional conservator, Piotr Frączek who prepared mock-ups of panel paintings and took photographs, and of Joanna Sobczyk who operated the environmental chamber during the mock-up exposure.

Author contribution LB: Conceptualization of the model, development of methodology, analysis and interpretation of the results, preparing manuscript. MYAJ: Development and validation of the model, performing calculations, data analysis and interpretation, NZ: development of the image analysis method, image analysis and statistical evaluation of craquelure patterns.

Funding This work was financed by the Polish National Agency for Academic Exchange [grant PPN/ PPO/2018/1/00004/U/00001] and the Norway Grants [project 2019/34/H/HS2/00581]. 


\section{Declarations}

Conflict of interest The authors declare that they have no known competing financial interests or personal relationships that could have appeared to influence the work reported in this paper.

Open Access This article is licensed under a Creative Commons Attribution 4.0 International License, which permits use, sharing, adaptation, distribution and reproduction in any medium or format, as long as you give appropriate credit to the original author(s) and the source, provide a link to the Creative Commons licence, and indicate if changes were made. The images or other third party material in this article are included in the article's Creative Commons licence, unless indicated otherwise in a credit line to the material. If material is not included in the article's Creative Commons licence and your intended use is not permitted by statutory regulation or exceeds the permitted use, you will need to obtain permission directly from the copyright holder. To view a copy of this licence, visit http://creativecommons.org/licen ses/by/4.0/.

\section{References}

ASHRAE (2019) Museums, galleries, archives and libraries. ASHRAE Handbook. Chap 24. American Society of Heating and Air-Conditioning Engineers, Atlanta

Bai T, Pollard DD, Gao H (2000a) Spacing of edge fracture in layered materials. Int J Fract 103:373-395

Bai T, Pollard DD, Gao H (2000b) Explanation for fracture spacing in layered materials. Nature 403:753-756

Bickersteth J (2016) IIC and ICOM-CC declaration on environmental guidelines. Stud Conserv 61(sup1):12-7

Bosco E, Suiker ASJ, Fleck NA (2020) Crack channelling mechanisms in brittle coating systems under moisture or temperature gradients. Int J Fract 225:1-30

Bosco E, Suiker ASJ, Fleck NA (2021) Moisture-induced cracking in a flexural bilayer with application to historical paintings. Theor Appl Fract Mec 112:102779

Bratasz $Ł$, Vaziri Sereshk MR (2018) Crack saturation as a mechanism of acclimatization of panel paintings to unstable environments. Stud Conserv. 63(sup1):22-27

Bratasz $Ł$, Akoglu KG, Kékicheff P (2020) Fracture saturation in paintings makes them less vulnerable to environmental variations in museums. Herit Sci 8:11

Bucklow SL (1997) The description of craquelure patterns. Stud Conserv 42:3129-3140

Bucklow SL (2000) Consensus in the classification of craquelure. Hamilton Kerr Inst Bull 3, Fitzwilliam Museum, Cambridge, pp. 61-73

Cennini C (1972) Il libro dell'arte (The book of art), 3d edn. DV Thompson, New Haven, CT

Giorgiutti-Dauphiné F, Pauchard L (2016) Painting cracks: a way to investigate the pictorial matter. J Appl Phys 120:065107

Hutchinson JW, Suo Z (1992) Mixed mode cracking in layered materials. Adv Appl Mech 29:63-191

Kramer RP, Schellen HL, van Schijndel AWM (2016) Impact of ASHRAE's museum climate classes on energy consumption and indoor climate fluctuations: full-scale measurements in museum Hermitage Amsterdam. Energy Build 130:286-294

Krzemień L, Łukomski M, Bratasz Ł, Kozłowski R, Mecklenburg MF (2016) Mechanism of craquelure pattern formation on panel paintings. Stud Conserv 61:324-330

Ma X, Lowensohn J, Burton JC (2019) Universal scaling of polygonal desiccation crack patterns. Phys Rev E 99:012802

Mecklenburg MF, Tumosa CS, Erhardt D (1998) Structural response of painted wood surfaces to changes in ambient relative humidity. In: Dorge V, Howlett FC (eds) Painted wood: history and conservation. The Getty Conservation Institute, Los Angeles, pp 464-83

Pauchard L, Giorgiutti-Dauphiné F (2020) Craquelures and pictorial matter. J Cult Herit 46:361-373

Rachwał B, Bratasz Ł, Krzemień L, Łukomski M, Kozłowski R (2012) Fatigue damage of the gesso layer in panel paintings subjected to changing climate conditions. Strain 48:474-481 
Shevchuk VA, Silberschmidt VV (2005) Semi-analytical analysis of thermally induced damage in thin ceramic coatings. Int J Solids Struct 42:4738-4757

Smithsonian (2015) Culmination of 20 years of Green, energy savings research. Smithsonian's museum conservation institute, Washington https://www.si.edu/mci/english/research/consulting/ MuseumEnvironment.html. Accessed 19 November 2019

Thomson G (1986) The museum environment, 2nd edn. Butterworths-Heinemann, London

Wood handbook (1999) Wood as an engineering material. General technical report FPL-GTR-113. Department of agriculture, forest service, forest products laboratory, Madison, WI, chap 4, p 3

Wu H, Pollard DD (1995) An experimental study of the relationship between joint spacing and layer thickness. J Struct Geol 17:887-905

Yin HM (2010) Fracture saturation and critical thickness in layered materials. Int J Solids Struct 47:1007-1015

Zhang R, Wood JD, Young CRT, Taylor AC, Balint DS, Charalambides MN (2021) A numerical investigation of interfacial and channelling crack growth rates under low-cycle fatigue in bi-layer materials relevant to cultural heritage. J Cult Herit 49:70-78

Publisher's Note Springer Nature remains neutral with regard to jurisdictional claims in published maps and institutional affiliations. 